\title{
Polyhedral Forms Obtained by Combinig Lateral Sheet of CP II-10 and Truncated Dodecahedron
}

\section{Marija Đ. Obradović \\ Associate Professor, University of Belgrade, Faculty of Civil engineering, \\ Belgrade \\ Milena Stavrić \\ Ass. Professor, Graz University of Technology, Faculty of Architecture, Graz, \\ Austria

\begin{abstract}
Albert Wiltsche
Ass. Professor, Graz University of Technology, Faculty of Architecture, Graz,
\end{abstract}

The paper analyzes the possibility of obtaining polyhedral shapes formed by combining polyhedral surfaces based on the segment surface of elongated concave pyramids of the second sort (CeP II-10, type A and type $B)$. In previous research, CP II type A and CP II type B were elaborated in detail. In this paper we discuss further potential of these polyhedral surfaces, on the example of combining them with Archimedean solid Truncated dodecahedron (U26). The faces of this solid consist of 12 decagons and 20 triangles. On the decagonal faces, decagonal polygons of the CeP II segments ( $\overline{C P}$ II-10) can be added, which provides the new polyhedral composite forms that are, furthermore, concave deltahedra. There are considered possibilities of obtaining polyhedral shapes by combining sheet segments $\overline{C P}$ II-10-A, as well as of $\overline{C P}$ II-10-B with U26. Finally, a couple of new shape suggestions are given: compound polyhedra, obtained by intersection of paired composite concave polyhedra originated in the described manner.

Keywords: concave polyhedra, composite polyhedra, truncated dodecahedron, $\overline{C P}$ II-10, augmentation, incavation

\section{INTRODUCTION}

This article considers procedures for creating obtainable new polyhedral shapes - composite polyhedra, comprised of concave polyhedral segments based on the geometry of the decagonal (elongated) concave pyramids of the second sort (CeP II-10) [10], [11], [6]. In previous research, the concave polyhedral shapes which will be used, are described in detail. In [10] are presented CP II type A, and in [11] CP II type B. In both cases, it is shown that there is a pattern by which we can form a concave pyramid of the second sort with regular polygons as bases, starting from $n=6$ to $n=9$, with the possibility of forming a lateral sheet of such a polyhedron even for $n=10$, but not the pyramid itself, as it comes to penetration of the lateral faces through the base. These polyhedral segments can be further combined with prisms and antiprisms, taking part in the formation of a closed space, producing a solid, so they can occur as integral parts of concave elongated and gyro-elongated pyramids of the second sort: CeP II-10, and CgeP II-10. Thus, in this paper, we use only a segment, lateral sheet of these polyhedra, which consists exclusively of equilateral triangles and can be folded by creasing a planar net.

The study of these forms represents a continuation of the research started with the concave cupolae of the second sort, (CC II), and the higher sorts, conducted in [4], [5], [7], [8], [9].

Since the base around which all the concave surfaces

Received: June 2016, Accepted: November 2016

Correspondence to: Marija Obradovic, Assistant

Professor, Faculty of Civil Engineering,

University of Belgrade, Serbia

E-mail: marijao@grf.bg.ac.rs

doi: $10.5937 /$ fmet17022560

(C) Faculty of Mechanical Engineering, Belgrade. All rights reserved concerned in the paper arise is a regular polygon decagon, we will seek possibilities of forming convex polyhedra which will also be deltahedra, consisting exclusively of equilateral triangles. Such an option is provided by using the central core in the form of Archimedean solid - truncated dodecahedron, which consists of twelve decagons and twenty equilateral triangles.

On the decagonal faces of truncated dodecahedron we join decagonal base of a segment of CeP II, and as the used polyhedral segments consist exclusively of equilateral triangles, with the remaining equilateral triangles of the Archimedean solid they will form a deltahedron.

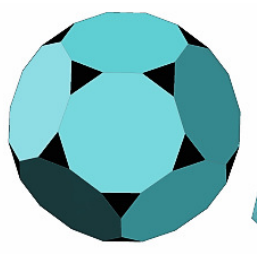

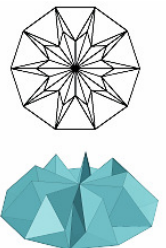

a)

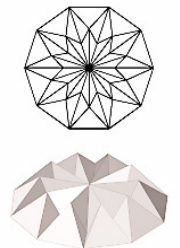

b)

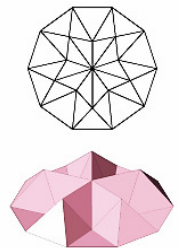

c)
Fig. 1: Truncated dodecahedron and three types of $\mathrm{CP}$ II10: a) $\overline{C P}$ II-10M, b) $\overline{C P}$ II-10m and c) $\overline{C P}$ H-10B

To facilitate following the process, let us simplify the terminology. Designate these polyhedral segments as $\overline{C P}$ II-10; they may be of type A with $5 \mathrm{n}=5 \cdot 10=50$ triangles in the sheet (Fig. 1a and b), and of type B with $3 n=3 \cdot 10=30$ triangles in the sheet (Fig. $1 \mathrm{c}$ ). The type A can be folded in two ways: with greater (major) height, $\overline{C P}$ II-10-M, and with lesser (minor) height, $\overline{C P}$ II-10$\mathrm{m}$, depending on the way of folding the edges of the planar net. The type $\mathrm{B}, \overline{C P}$ II-10-B, has just one 
possible variation and height. Within the truncated dodecahedron (Fig. 1, left), an Archimedean solid and uniform polyhedron (U26), there participate decagons, and if we adopt the congruence of these decagons with bases of mentioned polyhedral segments, we can perform joining these polyhedral shapes through augmentation or incavation of U26 by $\overline{C P}$ II- 10 .

Augmentations imply setting concave segments of $\overline{C P}$ II-10M, $\overline{C P}$ II-10m, and $\overline{C P}$ II-10B in the outside space of truncated dodecahedron, while incavations imply setting them in the interior space.

\section{ANALYSIS OF THE POSSIBLE NUMBER OF NEW SOLIDS FORMED BY JOINING $\overline{C P} \|-10$ ONTO FACES OF TRUNCATED DODECAHEDRON}

To discuss a number of possible ways of obtaining new solids through joining $\overline{C P}$ II-10 onto faces of truncated dodecahedron, we will apply a result from group theory, more specific - 3D symmetry groups, which is inevitable when it comes to the problems of determining the number of different permutations within one of the given group. It is Burnside's Lemma [1] (also known as Burnside's counting theorem, the Cauchy-Frobenius lemma or the orbit-counting theorem) i.e. its generalized form which follows from it - Pólya enumeration theorem [3].

Truncated dodecahedron belongs to icosahedral symmetry (point) group, so we will consider the possibility of adding new polyhedral surfaces - sheets of concave pyramids of the second sort, on the congruent decagonal faces, following the number of permutations of $\boldsymbol{n}$ elements on this symmetry group. As stated in the previous section, we can use three types of sheets: $\overline{C P}$ II-10-M, $\overline{C P}$ II-10-m and $\overline{C P}$ II-10-B. Since the aforementioned polyhedral segments can perform two interventions on truncated dodecahedron: augmentation and incavations, practically we have $3 \cdot 2=6$ possible interventions. However, it should be borne in mind that $\overline{C P}$ II-10-B, which has 5 planes of symmetry, can be embedded in two ways, unlike $\overline{C P}$ II-10 type $\mathrm{A}$, which have 10 planes of symmetry. Regardless the way $\overline{C P}$ II-10 type A would rotate around the orthogonal axis through the centroid of the decagon, the same solution would arise by joining it to the congruent face of truncated dodecahedron. $\overline{C P}$ II-10-B can be set on the decagonal face in two possible ways, differing in the angle of rotation around the centroid's axis, be it $0^{\circ}$, or $\left(\frac{2 \pi}{5}\right) / 2=36^{\circ}$. With these two cases, valid for $\overline{C P}$ II10-B, which can augment or incavate truncated dodecahedron, we get a total of 8 different ways of adding $\overline{C P}$ II-10 to the faces of truncated dodecahedron.

The problem comes down to the problem of determining the number of possible ways in which we could paint the faces of a dodecahedron (identical number of the accounted faces, arranged in exactly the same way as in a dodecahedron) using $m$ different colors. Thus, each of the interventions that we can apply, may be identified as 'color' in which we paint faces of truncated dodecahedron (Fig. 2). Also, the faces of the truncated dodecahedron that would remain 'vacant', i.e. without augmentation or incavation,will be counted as an corresponding 'color', so now we have a total of 9 colors.
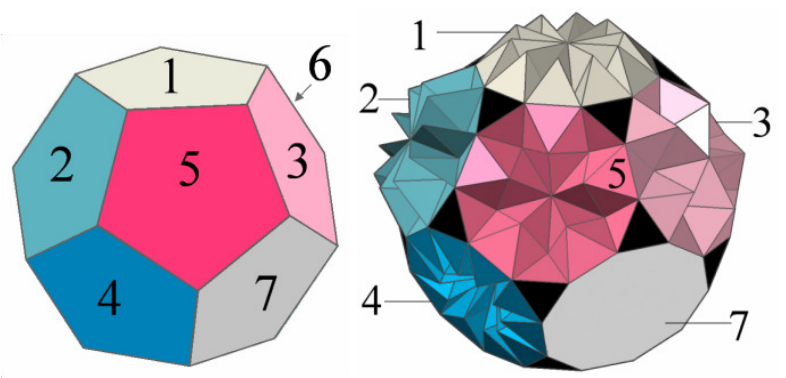

Fig. 2: Problem of colouring faces of dodecahedrron and the equivalent problem of adding CP II-10 onto the decagonal faces of the truncated dodecahedron

By application of Pólya enumeration theorem, we identify 60 rotation-permutation of dodecahedron [11].

Furthermore, based on the known general formula for finding the number of possible orbits for $m$ different colors on the symmetry group of order 60 :

$$
\begin{aligned}
& \frac{1}{60}\left(m^{12}+24 m^{4}+20 m^{4}+15 m^{6}\right)= \\
& =\frac{1}{60} n^{12}+\frac{1}{4} n^{6}+\frac{11}{15} n^{4}
\end{aligned}
$$

We will find the number of cases corresponding to application of 9 colors:

$$
\frac{1}{60} 9^{12}+\frac{1}{4} 9^{6}+\frac{11}{15} 9^{4}=4.707 .296 .61
$$

Thus, we see that the number of permutations for such a problem setting is too large to allow us to carry out even remotely practical systematization. Therefore, we will focus solely on those with the most picturesque examples of symmetry: when all the decagonal faces of truncated dodecahedron are colored by the same color. There will occur exactly eight cases of such interventions, because we adopt four augmentation cases: with two variations of $\overline{C P}$ II-10 type A, two possible orientations $\overline{C P}$ II-10 type $\mathrm{B}$ and four incavations cases by the same elements.

\section{FORMING A COMPOSITE POLYHEDRON BY ADDING CP II-10 INSTEAD OF THE DECAGONAL FACES OF TRUNCATED DODECAHEDRON}

In the process of forming a composite polyhedron out of the aforementioned segments, we must consider that, due to the geometrical characteristics of these polyhedral structures (described in detail in [6]) certain vertices of the $\overline{C P}$ II-10 penetrate decagonal basis, which is the reason why we use only segments of the concave pyramid. This will also happen with the faces of truncated dodecahedron, during the augmentations by the same elements.

So, in order to preserve criteria of obtaining a deltahedral surface - without penetrating faces and with all of the faces identical, we will remove the decagonal 
faces of truncated dodecahedron, leaving only the connecting triangles (Fig. 3).
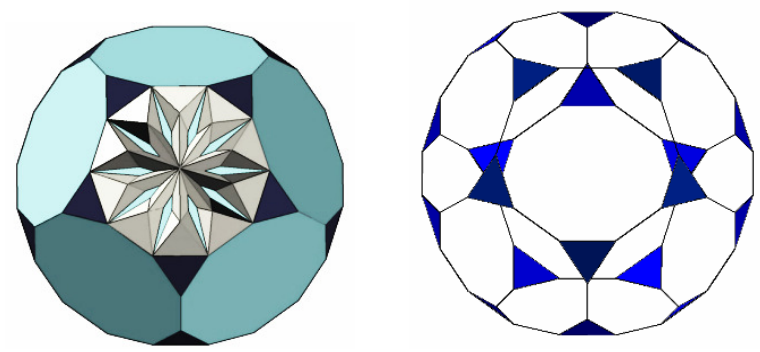

Fig. 3: Adding sheet of $\overline{\mathrm{CP}}$ II-10 on the faces of Truncated dodecahedron implies removing the decagonal faces in order to prevent penetrating the lateral faces through them

\section{TYPICAL EXAMPLES OF ARRANGEMENT OF $\overline{\mathrm{CP}}$ II-10 ACCORDING TO THE GEOMETRIC MATRIX OF TRUNCATED DODECAHEDRON}

In this section we give examples of typical cases of organizing $\overline{C P}$ II-10 on the decagonal faces of truncated dodecahedron. First, let us consider the cases of setting $\overline{C P}$ II-10 in the outside space of the initial truncated dodecaheron, i.e. augmentations of truncated dodecahedron.

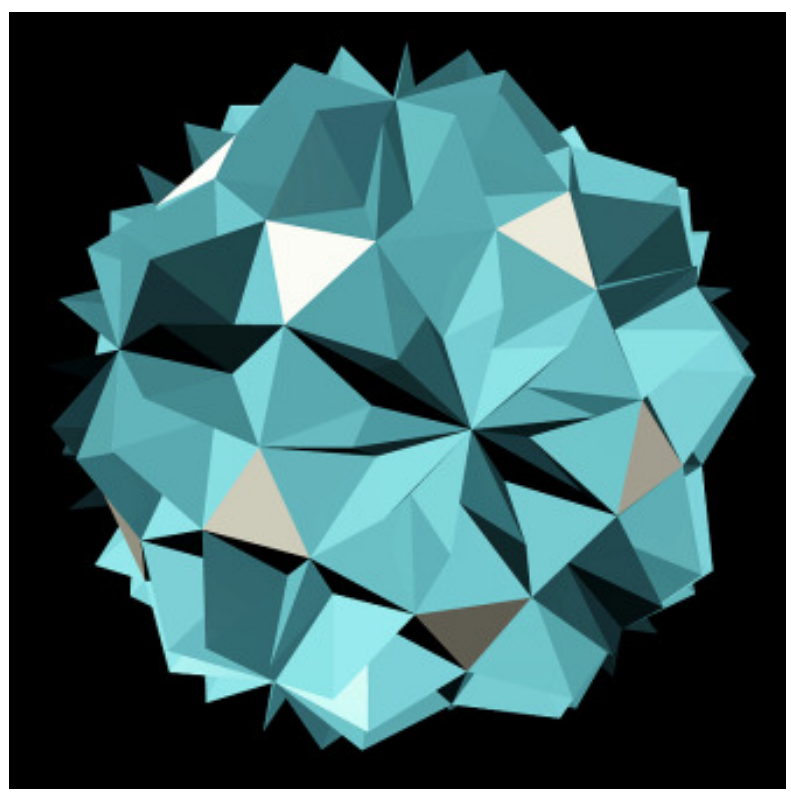

Fig. 4: Augmentation of truncated dodecahedron by $\overline{\mathrm{CP}}$ ॥I10-M

In Fig. 4 and Fig. 5 we see examples of $\overline{C P}$ II-10 type A arrangement on the spatial matrix of truncated dodecahedron, in accordance with what would be augmentations of truncated dodecahedron, only without its decagonal faces.

Truncated dodecahedron consist of 32 faces, 12 decagons (removed) and 20 triangles, 90 edges and 60 vertices. Twelve $\overline{C P}$ II-10-A, each having 50 faces, 80 edges, and 31 vertices, are arranged in such a way that they are connected by remaining 20 equilateral triangles of truncated dodecahedron. Consequently, we get (in both cases) concave deltahedron composed of $12 \cdot 50+20=620$ equilateral triangular faces, (80-
10) $\cdot 12+90=930$ edges, and $(31-10) \cdot 12+60=312$ vertices. The obtained values correspond to the results we get using Descartes-Euler formula: $\mathrm{V}+\mathrm{F}-\mathrm{E}=2$.

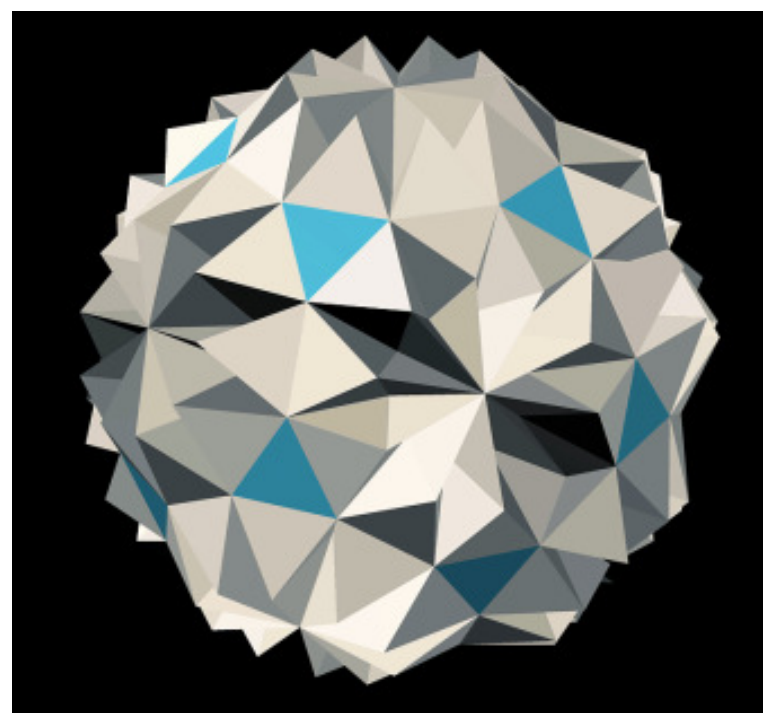

Fig. 5: Augmentation of truncated dodecahedron by $\overline{\mathrm{CP}}$ II10-m

The difference between the composite polyhedra obtained by adding $\overline{C P}$ II-10-M, or $\overline{C P}$ II-10-m onto faces of truncated dodecahedron is noticeable already by visual inspection. Although it is evident that the surfaces of these solids are identical (having the same number of triangular faces), sharper dihedral angles in the case of $\overline{C P}$ II-10-M reflect in the reduction in the total volume of the inner space of the composite polyhedron. More attention is paid to geometric measures, relations of the dihedral angles, surface-tovolume ratio etc. of these composite polyhedra, as well as for all the following examples, would reveal a potential for eventual application of these forms, which will be the subject of future research.

Examples of $\overline{C P}$ II-10 type B arrangement on the spatial matrix of truncated dodecahedron are presented in Fig. 6 and Fig. 7. Twelve $\overline{C P}$ II-10-B, each having 30 faces, 50 edges, and 21 vertices, are arranged in such a way that they are connected by remaining 20 equilateral triangles of truncated dodecahedron. Thus, we get (in both cases) concave deltahedron composed of $12 \cdot 30+20=380$ equilateral triangular faces, (5010) $\cdot 12+90=570$ edges and consequently (2110) $\cdot 12+60=192$ vertices. The obtained values correspond to the results we get using Descartes-Euler formula: $\mathrm{V}+\mathrm{F}-\mathrm{E}=2$.

As seen in Fig. 6 and Fig 7, the orientation of the $\overline{C P}$ II-10-B may be such that:

- The 'arm' of the spatial five-pointed star that appear as embossed pattern on the surface of $\overline{C P}$ II-10-B (shown in blue) is set so to bound the 'arm' of the adjacent $\overline{C P}$ II-10-B, for the position assigned as rotated by $0^{\circ}$ (Fig. 6)

- spatial five-pointed star that appear as embossed pattern on the surface of $\overline{C P}$ II-10-B (shown in blue) rotated by $36^{0}$ so that 'field' (shown in beige) adjoins the adjacent 'arm' 
- both the adjacent $\overline{C P}$ II-10-B are rotated by $36^{0} /$ oriented so that the 'field' adjoins the 'field' (Fig 7).

We demonstrated two of the three cases, the ones with the higher symmetry: 'arm to arm' and the case 'field to field'. The transient case "arm to field" is omitted because without clearly defined criteria on the number and position of the rotated segments, the number of these examples may vary.

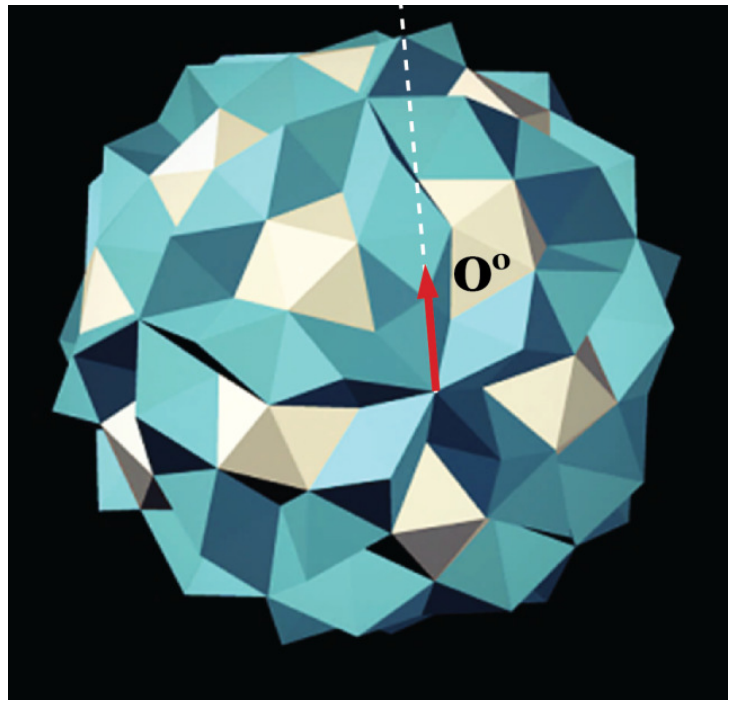

Fig. 6: Augmentation of truncated dodecahedron by $\overline{\mathrm{CP}}$ II10-B -'arm to arm'

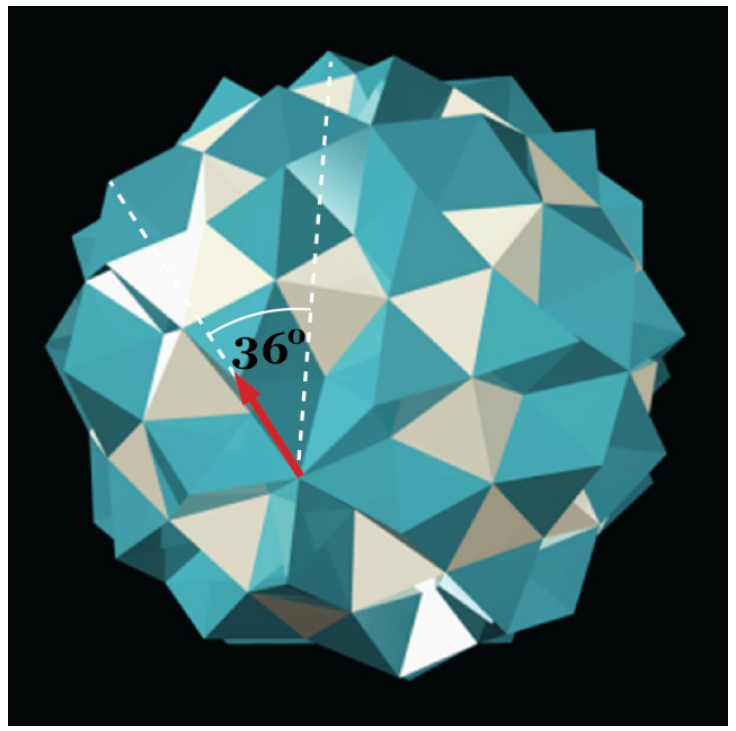

Fig. 7: Augmentation of truncated dodecahedron by $\overline{\mathrm{CP}}$ II10-B - 'field to field'“"

In the next four examples, we see the resulting composite polyhedra obtained by incavation of $\overline{C P}$ II10 within the space of a truncated dodecahedron.

Fig. 8 presents truncated dodecahedron incavated by $\overline{C P}$ II-10-M, and Fig. 9 presents truncated dodecahedron incavated by $\overline{C P}$ II- $10-\mathrm{m}$.

Fig. 10 presents truncated dodecahedron incavated by $\overline{C P}$ II-10-B oriented 'arm to arm', while Fig. 11 shows the case of incavation by $\overline{C P}$ II-10-B oriented 'field to filed'.

Basic characteristics, such as the number of faces, edges and vertices will be identical to the examples with
$\overline{C P}$ II-10 oriented in the outside space. Surfaces of the paired solids are also identical, but not the volumes.

In this way, we have shown the eight most typical representatives of composite polyhedra formed by joining $\overline{C P}$ II-10 onto faces of truncated dodecahedron.

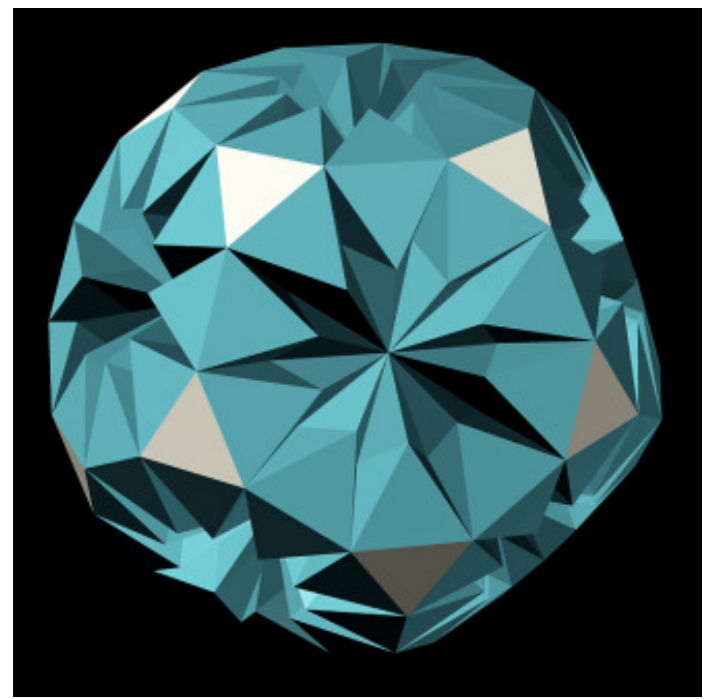

Fig. 8: Incavation of truncated dodecahedron by $\overline{\mathrm{CP}}$ II-10-M

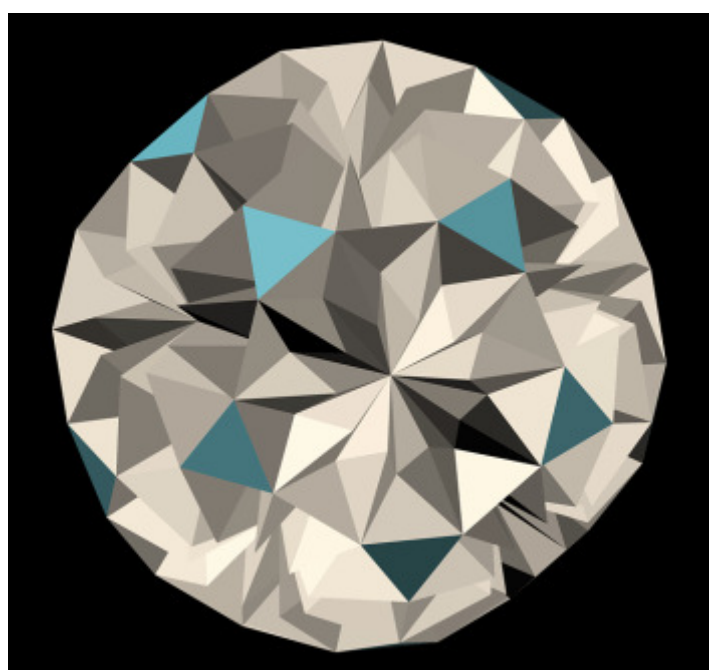

Fig. 9: Incavation of truncated dodecahedron by $\overline{\mathrm{CP}}$ II-10-m

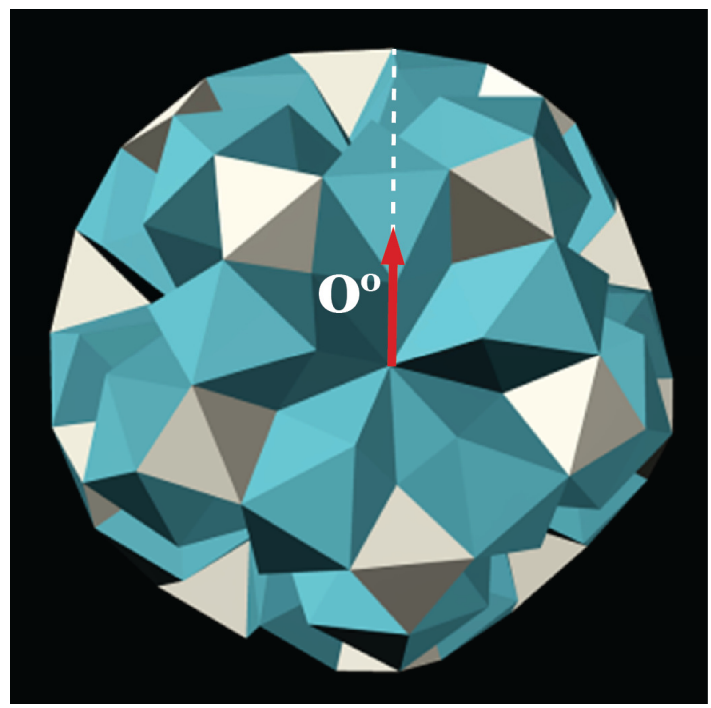

Fig. 10: Incavation of truncated dodecahedron by $\overline{\mathrm{CP}}$ ॥I10-B 'arm to arm' 


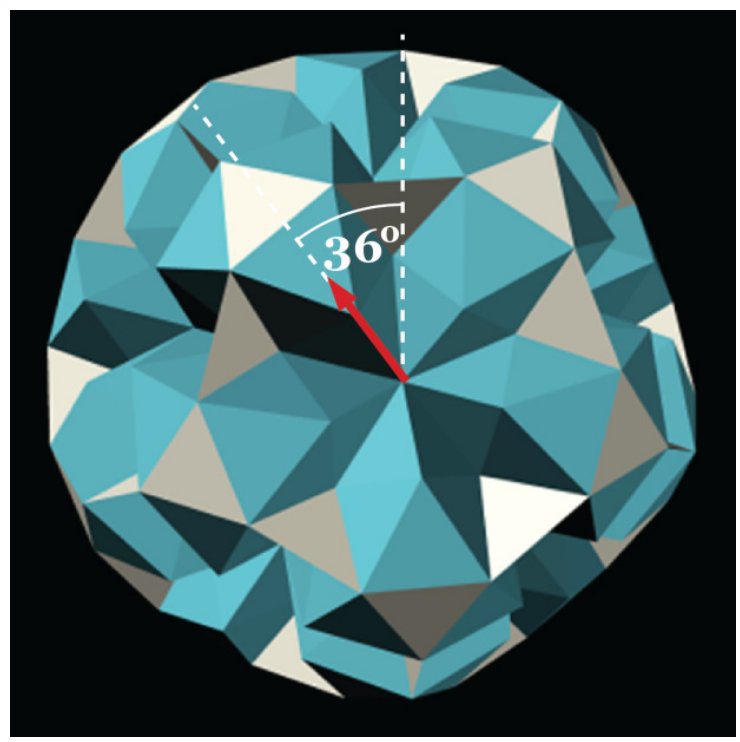

Fig. 11: Incavation of truncated dodecahedron by $\overline{\mathrm{CP}}$ II-10B 'field to field'،

\section{COMPOUND POLYHEDRA FORMED BY MER- GING THE PREVIOUS CASES INTO ONE SOLID}

A polyhedral compound is a polyhedral structure composed of two or more polyhedra that share a common center. Although compounds are usually a combination of a polyhedron with its dual [12], in this case we will adopt a polyhedral compound as obtained by uniting two composite polyhedra formed in the manner described in the previous section.

In order to obtain compound polyhedron, we unite two of the obtained concave composite polyhedra having a common center, congruent (reimaining) triangular faces of the truncated dodecahedron, and are augmented or incavated by the related segments. Under relation, it is understood that we combine two types of augmentations (or incavations) of truncated dodecahedron by $\overline{C P}$ II-10 which occurred by corrugating an identical planar net when obtaining lateral sheet: type A with another type A, and type B with oppositely oriented type B.

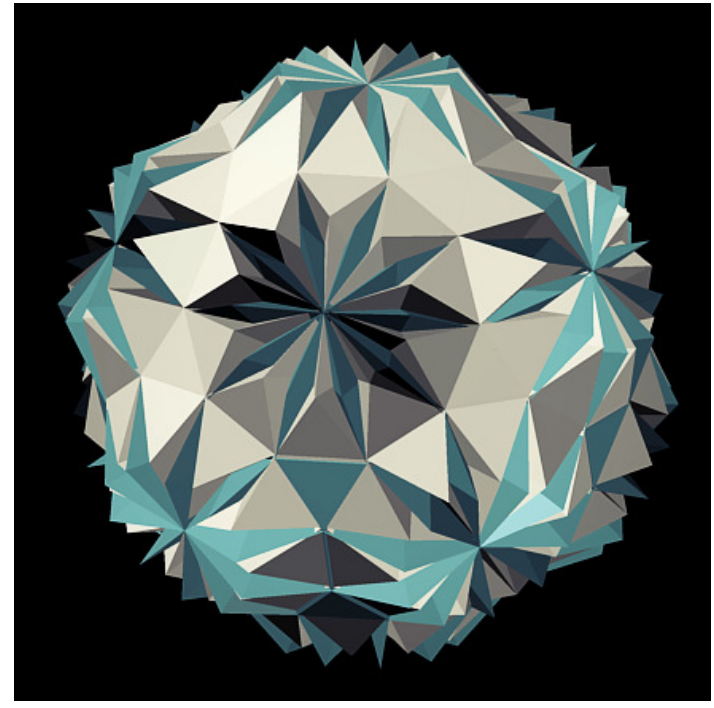

Fig. 12: Compound polyhedron made of two truncated dodecahedra augmented by $\overline{\mathrm{CP}} \| \mathrm{I}-10 \mathrm{M}$ and $\overline{\mathrm{CP}} \| \mathrm{I}-10 \mathrm{~m}$

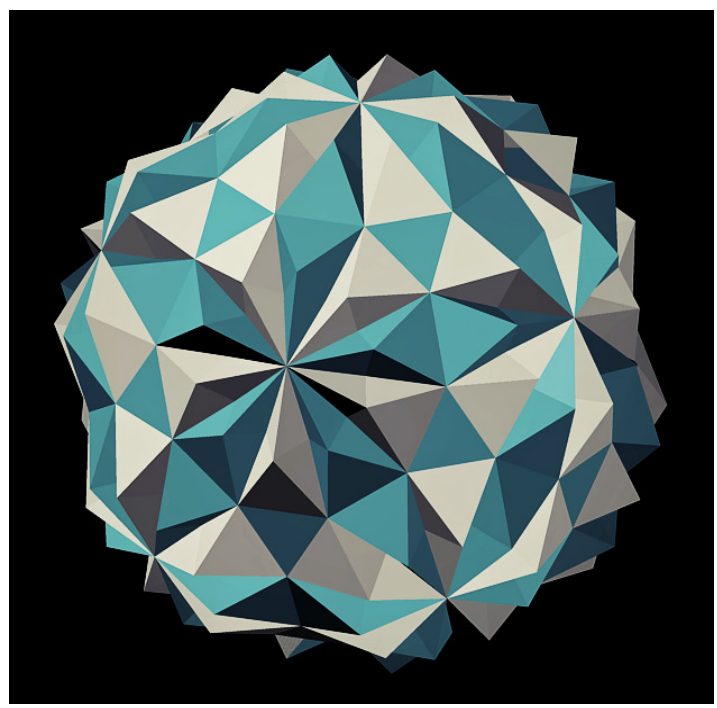

Fig. 13: Compound polyhedron made of two truncated dodecahedra augmented by $\overline{\mathrm{CP}}$ II-10 $\mathrm{B}$ 'arm to arm'

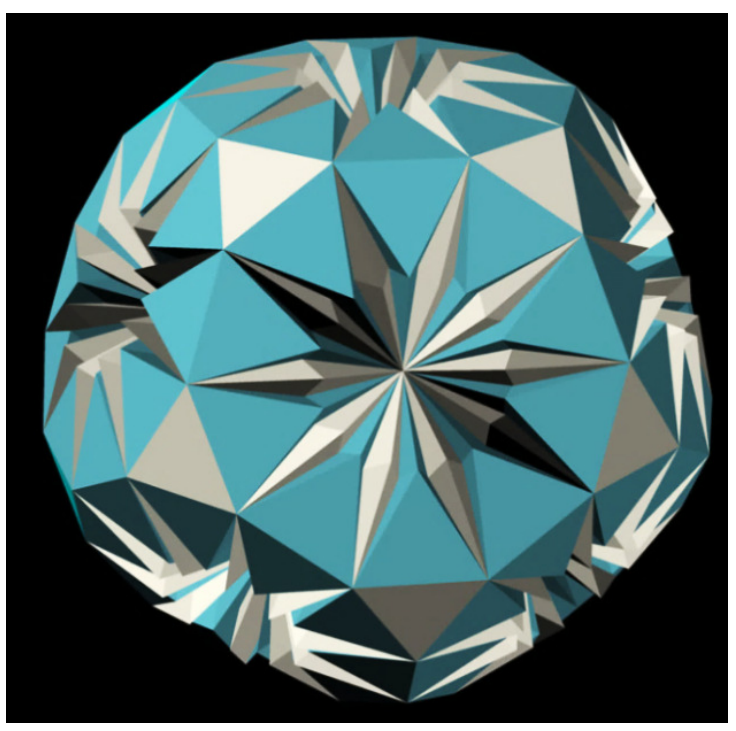

Fig. 14: Compound polyhedron made of two truncated dodecahedra incavated by $\overline{\mathrm{CP}} \mathrm{II}-10 \mathrm{M}$ and $\overline{\mathrm{CP}} \mathrm{II}-10 \mathrm{~m}$

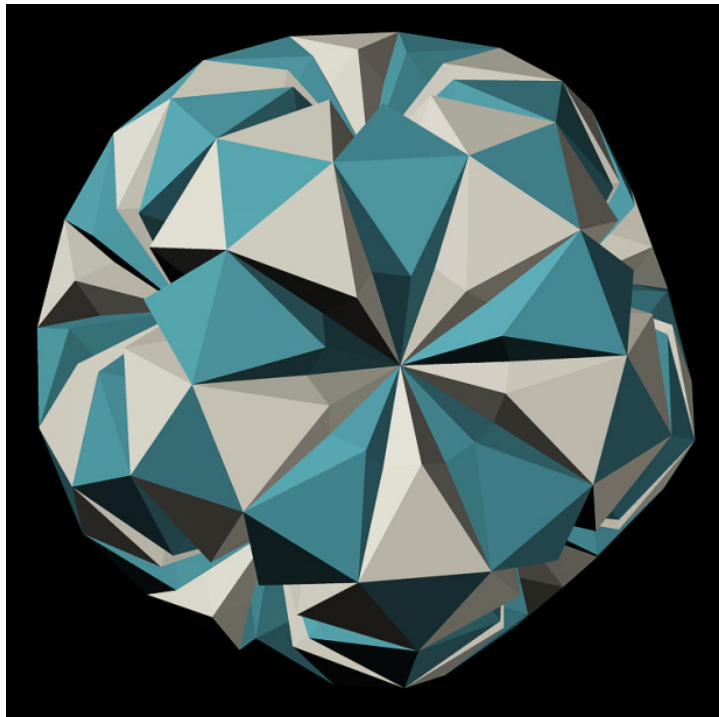

Fig. 15: Compound polyhedron made of two truncated dodecahedra incavateded by $\overline{\mathrm{CP}}$ II-10B 'arm to arm' and $\overline{\mathrm{CP}}$ II-10B - 'field to field'“ 
Thus, we will overlap with congruent centers two composite polyhedra obtained by interventions on truncated dodecahedra:

- augmented by two types of $\overline{C P}$ II-10A: $\overline{C P}$ II-10M and $\overline{C P}$ II-10m (Fig 12)

- augmented by two $\overline{C P}$ II-10B: $\overline{C P}$ II-10B 'arm to arm' and 'filed to field' (Fig 13)

- incavated by two types of $\overline{C P}$ II-10A:. $\overline{C P}$ II-10M and $\overline{C P}$ II-10m (Fig 14)

- incavated by two orientations of $\overline{C P}$ II-10B: $\overline{C P}$ II$10 \mathrm{~B}$ "arm to arm" and $\overline{C P}$ II-10B "filed to field" (Fig 15).

Forms that we generate in this manner will share the maximal number of common faces with the truncated dodecahedron, because they will have the compliant polar arrangements of the composing elements.

\section{CONCLUSIONS}

The paper gives a number of possible concave composite polyhedra that may arise by adding segments of CeP II-10: $\overline{C P}$ II-10, onto decagonal bases of truncated dodecahedron. It is shown that the number (over 4.7 billion) is far beyond the possibilities of visualizing each of them individually. Hence, only the most typical examples of adding one type of $\overline{C P}$ II-10 to all the decagonal faces are given. They may be placed in outer space, making augmentations of truncated dodecahedron, or dented into the interior space, making incavations. In addition to the eight elementary cases are given, and also four cases of the compound polyhedra formation, obtained by overlapping two examples of matching composite polyhedra with a common center (overlapped two augmentations with $\overline{C P}$ II-10-A and overlapped two augmentations with $\overline{C P}$ II-10-B). Considering the properties of the newly obtained polyhedral structures, even just by visual inspection, we can then look for the most appropriate area of application of these solids.

\section{ACKNOWLEDGMENT}

This paper is partly supported by MPNTR grant No. III44006.

\section{REFERENCES}

[1] Burnside, W. Theory of Groups of Finite Order, Cambridge University Press, 1897.

[2] Emmerich D.G. Composite polyhedra (Polyedres composites) - Topologie Strucutrale \#13, 1986.

[3] Harary, F. "Pólya's Enumeration Theorem." Graph Theory Reading, MA: Addison-Wesley, pp. 180184, 1994.

[4] Mišić S., Obradović M. Đukanović G.: Composite Concave Cupolae as Geometric and Architectural Forms, Journal for Geometry and Graphics, 2015. Vol.19. No 1. pp 79-91.

[5] Obradović M., A Group Of Polyhedra Arised As Variations Of Concave Bicupolae Of Second Sort,
Proceedings of $3 r d$ International Scientific Conference MoNGeometrija 2012, ISBN 978-867892-405-7 Novi Sad, jun 21-24. 2012. pp. 95-132.

[6] Obradović M., Konstruktivno - geometrijska obrada toroidnih deltaedara sa pravilnom poligonalnom osnovom, $\mathrm{PhD}$ thesis, Arhitektonski fakultet Univerziteta u Beogradu, 2006.

[7] Obradović M., Mišić S., Concave Regular Faced Cupolae of Second Sort, Proceedings of 13th ICGG, July 2008, Dresden, Germany, El. Book, pp. $1-10$.

[8] Obradović M., Mišić S., Petrović M.: Investigating Composite Polyhedral forms obtained by combining concave cupolae of II sort with Archimedean Solids, in: Proceedings of $3 r d$ International Scientific Conference MoNGeometrija 2012, Novi Sad, 21-24. 06. 2012. pp. $109-123$.

[9] Obradović M., Mišić S., Popkonstantinović B., Petrović M., Malešević B., Obradović R., Investigation of concave cupolae based polyhedral structures and their potential application in architecture, TTEM Journal, Vol.8., No.3, 8/9 2013, pp. 1198-1214.

[10] Obradović M., Mišić S., Popkonstantinović B.: Concave Pyramids of Second Sort - The Occurrence, Types, Variations, in: Proceedings of 4th International Scientific Conference on Geometry and Graphics, moNGeometrija 2014, Vol 2, 20-22. 06. 2014.Vlasina, Serbia, pp. 157 -168.

[11] Obradović M., Mišić S., Popkonstantinović B.: Variations of Concave Pyramids of Second Sort with an Even Number of Base Sides, Journal of Industrial Design and Engineering Graphics (JIDEG) - The SORGING Journal, Volume 10, Special Issue, Fascicle 1, pp. 45-50, 2015.

[12] W. Hart George, Compound Polyhedra, Wirtual Polyhedra, (C)1996.

http://www.georgehart.com/virtualpolyhedra/compounds-info.html

\section{ПОЛИЕДАРСКЕ ФОРМЕ НАСТАЛЕ СПАЈАҢЕМ ОМОТАЧА СР ІІ-10 И ЗАРУБЉЕНОГ ДОДЕКАЕДРА}

\section{М. Обрадовић, М. Ставрић, А. Вилче}

У раду се анализира могућност добијања сложених полиедарских облика комбиновањем сегмената елонгираних конкавних пирамида друге врсте (СеР II-10, тип А и тип Б). У претходним истраживањима, CP II су детаљно обрађени. Истражује се даљи потенцијал ових полиедарских површи, на примеру њиховог спајања са Архимедовим телом, зарубљеним додекаедром чије се стране састоје од декагона и троуглова. На декагоналне стране овог тела додајемо подударне полигоне полиедарских сегмената (ㅍ II-10), чиме добијамо нове форме конкавних композитних полиедара, као и могућност њиховог даљег преклапања у полиедарска једињења. 